\title{
Influence of Age and Body Mass Index on Total and Segmental Colonic Transit Times in Constipated Subjects
}

\author{
Michel Bouchoucha, ${ }^{1,2 *}$ Marinos Fysekidis, ${ }^{3}$ Pierre Rompteaux, ${ }^{2}$ Gheorge Airinei, ${ }^{2}$ Jean-Marc Sabate, ${ }^{2}$ and Robert Benamouzig ${ }^{2}$ \\ ${ }^{1}$ Université Paris V René Descartes, Paris, France; ${ }^{2}$ Service de'gastroentérologie, Hôpital Avicenne, Bobigny, France; and ${ }^{3}$ Service d'endocrinologie \\ et diabétologie, Hôpital Avicenne, Bobigny, France
}

\section{Background/Aims}

Discordant data are found in the literature for the relationships between total and segmental colonic transit time (CTT) and demographic parameters. The aim of this study is to examine the influence of age, and body mass index (BMI) on total and segmental CTT in constipated subjects.

\section{Methods}

We included 354 constipated patients on this cross-sectional study. According to the Rome III criteria, patients were classified as having irritable bowel syndrome with constipation, or functional constipation. All patients filled the Bristol stool form, and reported the severity of constipation, bloating, and abdominal pain on a 10-point Likert scale. Total and segmental CTT were measured using radiopaque markers.

\section{Results}

Females were $84 \%$ of patients, with a mean age of $46.0 \pm 15.9$ years. The association between total and segmental CTT with age and BMI was significant after adjustment for gender, clinical phenotype, the presence of defecation disorders, and abdominal pain or bloating intensity despite the severity of symptoms, and the frequency of defecation disorders were higher in irritable bowel syndrome with constipation than in functional constipation patients. By comparison with subjects less than 30 years, rectosigmoid transit time (RSTT) was lower in patients between 30 and 60 years. Age was negatively associated with RSTT $(P=0.004)$. By comparison with patients with normal BMI, RSTT and total CTT were lower in patients of the overweight group. BMI was negatively associated with $\operatorname{RSTT}(P<0.001)$. The severity of constipation was correlated with total $(P<0.001)$, right $(P=0.002)$, and left CTT $(P=0.049)$.

\section{Conclusion}

Age and BMI are both associated with RSTT in constipated patients.

(J Neurogastroenterol Motil 2019;25:258-266)

\section{Key Words}

Abdominal pain; Constipation; Functional gastrointestinal disorders; Irritable bowel syndrome

Received: October 2, 2018 Revised: December 4, 2018 Accepted: March 13, 2019

(a) This is an Open Access article distributed under the terms of the Creative Commons Attribution Non-Commercial License (http://creativecommons. org/licenses/by-nc/4.0) which permits unrestricted non-commercial use, distribution, and reproduction in any medium, provided the original work is properly cited.

*Correspondence: Michel Bouchoucha, MD, PhD CEFRED (centre d'exploration fonctionnelle et de rééducation digestive), Service de gastro-entérologie, Hôpital Avicenne, 125 rue de Stalingrad, 93009 Bobigny Cedex, France Tel: +33-1-48957432, Fax: +33-1-48957437, E-mail: michel.bouchoucha@avc.aphp.fr 


\section{Introduction}

Constipation is frequently used to describe many functional bowel disorders defined by the Rome criteria, such as functional constipation (FC), irritable bowel syndrome (IBS) with constipation (IBS-C), ${ }^{1}$ or functional anorectal disorders with pelvic floor dysfunction, such as defecation disorders (DD). ${ }^{2}$ Abdominal pain is also frequently associated with constipation. ${ }^{3}$

In constipated patients, the influence of age has been mainly studied in children and in the elderly. In children, a relative stagnation was found in the rectosigmoid area. ${ }^{4}$ Old age is a factor that is frequently associated with gastrointestinal dysmotility. ${ }^{5}$ The term "presbyesophagus" was proposed to explain the phenomenon that occurs in the esophagus. ${ }^{6}$ In older patients, additional risk factors for constipation include decreased mobility, dehydration, poor fiber intake, and associated pathologies. ${ }^{7}$

The relationship between constipation and body mass index (BMI) is known to have a bimodal distribution with age. Under the age of 18 years, constipated boys and girls presented a higher prevalence of obesity compared with a control-group matched for age and gender. Overweight, constipated children seemed to constitute a distinct clinical group, with a higher prevalence of the male gender, and increased rates of psychological or behavioral disorders. ${ }^{8}$ However, in adolescents the frequency of constipation was not associated with increased weight. A recent study in primary care patients found an increased duration of constipation in overweight Iranian children. Furthermore, in the same ethnic group, another epidemiological study found that $60 \%$ of constipated adults were overweight. ${ }^{9}$ In contrast, a study in Chinese population found that a higher proportion of patients with slow transit constipation have a low BMI. ${ }^{10}$ A large sample of the French population have also been studied by our group, and no association between constipation and BMI was determined. ${ }^{11}$ These results imply that ethnic differences can modify the relationship between constipation and BMI. ${ }^{12}$ In the general population, 2 studies showed a positive correlation between increased BMI and diarrhea ${ }^{13}$ in young adults, ${ }^{14}$ and in overweight IBS patients that presented decreased rectosigmoid transit time (RSTT) compared to patients with normal weight. ${ }^{15}$

An objective assessment of constipation is based on the measure of total and segmental colonic transit times (CTT). However, CTT depends also on factors that modify stool frequency and stool consistency, including lifestyle factors (diet, stress, etc). ${ }^{16}$ In constipated subjects, dietary fiber intake increased stool frequency ${ }^{17}$ without improving painful defecation. ${ }^{18}$
The aim of the present study is to evaluate the influence of age and BMI on the self-reported severity of symptom (ie, constipation, bloating, and abdominal pain), clinical phenotype (IBS-C, FC, and DD), and total or segmental CTT in constipated patients.

\section{Materials and Methods}

\section{Study Design}

This cross-sectional study was registered to the French National Agency for drug safety (Agence Nationale de Sécurité du Médicament et des produits de santé, decision number 2017-A01513-50).

\section{Ethical Consideration}

The authors assert that all procedures contributing to this work comply with the ethical standards of the relevant national and institutional committees on human experimentation and with the Helsinki Declaration of 1975, as revised in 2008.

\section{Subjects}

We included 354 consecutive outpatients referred to the Gastroenterology Clinic of the Avicenne Hospital (Bobigny, France) for chronic constipation between January 2012 and July 2017. Clinical description for some of these patients was previously published. ${ }^{19}$ The initial colonic endoscopic examination, and the examination for any organic diseases (ie, metabolic, endocrine, neurologic, and psychiatric etiologies) did not present any organic cause to explain the patients' complaints. ${ }^{1}$

\section{Clinical and Physiological Evaluation}

All patients filled a standard clinical Rome III questionnaire. Moreover, they reported stool consistency using the Bristol stool scale and a self-evaluation of the severity of their symptoms during the last week (constipation, bloating, and abdominal pain) using a 10-point (0 to 9) Likert scale.

Physiological tests included a standard anorectal manometry and the measure of total and segmental CTT using radiopaque markers with the method "Single marker-Multiple ingestion-Single film." ${ }^{20}$ Briefly, 12 radiopaque markers within a gelatin capsule were ingested from day 1 to day 6 at 9 AM. A plain film of the abdomen was taken on the seventh day at 9 AM. to measure transit times. Markers were localized and counted in the different segments of the large bowel according to bony landmarks and gaseous outlines, as previously described. ${ }^{21}$ The spinal column served to separate the right from the left colon; the pelvic inlet was taken to separate the 
rectosigmoid area from the left colon. Segmental and total CTT were calculated according to the distribution of the markers in the different segments of bowel. This was done using the equation $\mathrm{CTT}=(\mathrm{n} \times \Delta \mathrm{T}) / \mathrm{N}$, where $\Delta \mathrm{T}$ is the time between the 2 ingestions of markers, $\mathrm{N}$ is the number of markers ingested at each intake, and $\mathrm{n}$ is the number of markers in the zone of interest. According to the values used in the present study $(\mathrm{N}=12$ radiopaque markers, $\Delta \mathrm{T}=24$ hours $)$ CTT $=(\mathrm{n} \times 24) / 12=2 \times \mathrm{n}$. CTT then varied between 0 hour and 144 hours. In addition, patients with DD had dynamic magnetic resonance defecography. ${ }^{22}$

Patients were divided into 5 age groups ( $<30$ years, 30 to $<$ 45 years, 45 to $<60$ years, 60 to $<75$ years, and $\geq 75$ years), and into 5 BMI groups ( $<18.5 \mathrm{~kg} / \mathrm{m}^{2}$, underweight; 18.5 to $<25 \mathrm{~kg}$ ) $\mathrm{m}^{2}$, normal weight; 25 to $<30 \mathrm{~kg} / \mathrm{m}^{2}$, overweight; 30 to $<35 \mathrm{~kg} /$ $\mathrm{m}^{2}$, obesity; and $\geq 35 \mathrm{~kg} / \mathrm{m}^{2}$, morbid obesity).

\section{Definition of Constipation Subtypes}

All patients had hard or lumpy stools for more than $25 \%$ of their bowel movements, and loose or watery stools for less than $25 \%$ of their bowel movements. ${ }^{1}$ The different groups of patients were deduced from the Rome III criteria. ${ }^{1}$

(1) IBS-C was defined by recurrent abdominal pain or discomfort for at least 3 days per month in the last 3 months, associated with 2 or more of the following: improvement with defecation and/ or onset associated with a change in frequency and/or form (appearance) of stool.

(2) FC was diagnosed when insufficient criteria for a diagnosis of IBS were met, and 2 or more of the following were identified: (a) straining during at least 25\% of defecations, (b) lumpy or hard stools in at least $25 \%$ of defecations, (c) sensation of incomplete evacuation for at least $25 \%$ of defecations, (d) sensation of anorectal obstruction/blockage for at least $25 \%$ of defecations, (e) manual maneuvers to facilitate at least $25 \%$ of defecations, and (f) fewer than 3 defecations per week.

(3) DD were defined by impaired defecation in 2 of the following 3 tests; ${ }^{2}$ abnormal balloon expulsion test (inability to expel a 50 $\mathrm{mL}$ water-filled balloon within 1-2 minutes), ${ }^{23}$ abnormal anorectal evacuation pattern, and impaired rectal evacuation by imaging (inability to evacuate $\geq 50 \%$ retention of rectal content during defecography or MR defecography). ${ }^{24}$

(4) As previously described, patients were classified as having right, left, or rectosigmoid delay according to the largest segmental CTT; ie, right colon delay was defined by right CTT was longer than left CTT and RSTT. ${ }^{25}$

\section{Statistical Methods}

Statistical analyses were carried out using SPSS version 20.0 (IBM Corp, Armonk, NY, USA). P-values less than 0.05 were considered statistically significant. Data were summarized in frequencies with percentages for categorical variables and means with standard deviation for continuous variables. The chi-square $\left(\chi^{2}\right)$ test was used to compare categorical variables, and analysis of variance (ANOVA) was used for the analysis of quantitative variables (age, BMI, and stool form). Significant ANOVA analysis led to posthoc tests with Bonferroni adjustment for multiple tests. In addition, a linear regression model adjusted for age, BMI, gender, clinical group, the presence of painful constipation, pelvic floor dysfunction, and symptom intensity was used to assess the relationship between total and segmental CTT.

\section{Results}

\section{Clinical and Physiological Description of Constipated Patients}

The 354 constipated patients included in the present study were divided into 139 IBS-C patients and 215 FC patients, while 243 (69\%) had DD. The mean age of the patients was $46.0 \pm$ 15.4 years. Ninety percent of IBS-C patients were females and had a lower BMI than FC patients. IBS-C patients had a similar stool form but reported more severe constipation, bloating, and abdominal pain (Supplementary Table 1). DD patients had a different stool form but reported more severe constipation, bloating, and abdominal pain (Supplementary Table 1). The characteristics of the constipated subjects according to gender is shown in Supplementary Table 2. In constipated patients, age, BMI, total CTT, and segmental CTT were not different according to the presence of DD (Supplementary Table 3).

\section{Characteristics of Constipation According to Age}

Patients were predominantly female $(\mathrm{n}=297 ; 84 \%)$, but equally distributed in all age groups. There were no differences in BMI, the severity of constipation, bloating, and abdominal pain amongst age groups. By comparison, with patients $<30$ years (Table 1), CTT in the left part of the colon was increased in the 45 to $<60$ year age group, and CTT in the rectosigmoid area was decreased in patients from 30 to $<60$ year olds (Fig. 1).

The linear regression shows that age is positively correlated with the left CTT $(P=0.018)$ and negatively associated with the 
Table 1. Characteristics of the Different Groups of Constipated Subjects According to Age Group

\begin{tabular}{|c|c|c|c|c|c|c|c|}
\hline \multirow{2}{*}{ Variables } & \multirow{2}{*}{ Total } & \multicolumn{5}{|c|}{ Age group (yr) } & \multirow{2}{*}{$P$-value } \\
\hline & & $<30$ & $30-<45$ & $45-<60$ & $60-<75$ & $\geq 75$ & \\
\hline \multicolumn{8}{|l|}{ Demographics } \\
\hline Number & $354(100)$ & $68(19)$ & $102(29)$ & $118(33)$ & $47(13)$ & $19(5)$ & \\
\hline Age (yr) & $46.0 \pm 15.9$ & $24.7 \pm 3.4$ & $38.1 \pm 4.3$ & $51.4 \pm 4.3$ & $66.8 \pm 4.4$ & $79.9 \pm 3.9$ & - \\
\hline Female gender & $297(84)$ & $59(87)$ & $87(85)$ & $99(84)$ & $36(77)$ & $16(84)$ & 0.659 \\
\hline $\operatorname{BMI}\left(\mathrm{kg} / \mathrm{m}^{2}\right)$ & $25.5 \pm 5.5$ & $24.2 \pm 6.5$ & $25.2 \pm 5.1$ & $26.4 \pm 5.8$ & $25.6 \pm 4.3$ & $26.0 \pm 4.0$ & 0.130 \\
\hline \multicolumn{8}{|l|}{ Clinical phenotype } \\
\hline Functional constipation & $215(61)$ & $37(17)$ & $58(27)$ & $79(37)$ & $26(12)$ & $15(7)$ & 0.141 \\
\hline IBS-C & $139(39)$ & $31(22)$ & $44(32)$ & $39(28)$ & $21(15)$ & $4(3)$ & \\
\hline Defecation disorders & $243(69)$ & $47(69)$ & $75(74)$ & $80(68)$ & $27(57)$ & $14(74)$ & 0.387 \\
\hline \multicolumn{8}{|l|}{ Scales } \\
\hline LS-constipation & $6.0 \pm 2.5$ & $6.3 \pm 2.2$ & $5.8 \pm 2.3$ & $5.8 \pm 2.6$ & $5.8 \pm 2.7$ & $6.9 \pm 2.8$ & 0.325 \\
\hline LS-bloating & $5.1 \pm 2.9$ & $5.0 \pm 2.8$ & $5.5 \pm 2.7$ & $5.1 \pm 3.0$ & $5.0 \pm 2.9$ & $4.1 \pm 3.4$ & 0.371 \\
\hline LS-abdominal pain & $4.2 \pm 2.9$ & $4.5 \pm 2.9$ & $4.3 \pm 3.0$ & $4.0 \pm 3.0$ & $4.4 \pm 3.0$ & $3.0 \pm 2.8$ & 0.337 \\
\hline Bristol stool form & $2.1 \pm 1.3$ & $2.1 \pm 1.3$ & $2.2 \pm 1.3$ & $2.1 \pm 1.3$ & $2.0 \pm 1.4$ & $2.1 \pm 1.3$ & 0.929 \\
\hline \multicolumn{8}{|l|}{ CTT (hr) } \\
\hline Right CTT & $22.9 \pm 21.5$ & $23.8 \pm 23.1$ & $23.1 \pm 24.6$ & $23.2 \pm 20.5$ & $19.4 \pm 13.8$ & $26.4 \pm 20.4$ & 0.753 \\
\hline Left CTT & $28.2 \pm 22.4$ & $22.6 \pm 16.9$ & $25.0 \pm 21.1$ & $32.5 \pm 24.4^{\mathrm{a}}$ & $32.5 \pm 24.4$ & $28.3 \pm 23.3$ & 0.014 \\
\hline RSTT & $17.9 \pm 17.2$ & $24.4 \pm 21.7$ & $16.5 \pm 17.4^{\mathrm{a}}$ & $16.4 \pm 14.2^{\mathrm{a}}$ & $16.6 \pm 16.7$ & $13.7 \pm 10.5$ & 0.012 \\
\hline Total CTT & $69.9 \pm 43.3$ & $75.6 \pm 54.0$ & $64.7 \pm 39.5$ & $71.8 \pm 42.1$ & $68.5 \pm 40.8$ & $69.5 \pm 32.5$ & 0.570 \\
\hline
\end{tabular}

${ }^{\mathrm{a}} P<0.05$ by comparison to the youngest patients $(<30$ years).

$P<0.05$ was considered significant.

BMI, body mass index; IBS-C, irritable bowel syndrome with constipation; LS, Likert scale; CTT, colonic transit time; RSTT, rectosigmoid transit time.

Quantitative parameters are expressed as mean $\pm \mathrm{SD}$ and qualitative parameters are shown as $\mathrm{n}(\%)$.

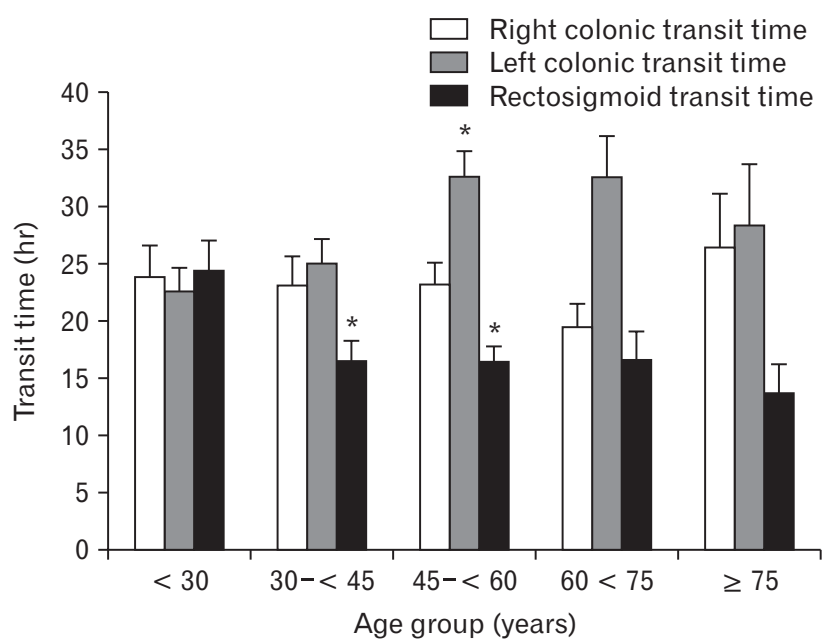

Figure 1. Relationship between age and segmental colonic transit time in constipated patients. By comparison with young adult patients ( $<30$ years), constipated patients between 45 years and 60 years have delayed transit in the left part of the colon $\left({ }^{\star} P<0.05\right)$. In contrast, patients aged from 30 years to 45 years and patients aged from 45 years and 60 years have shorter transit in the rectosigmoid area than younger patients $\left({ }^{\star} P<0.05\right)$.

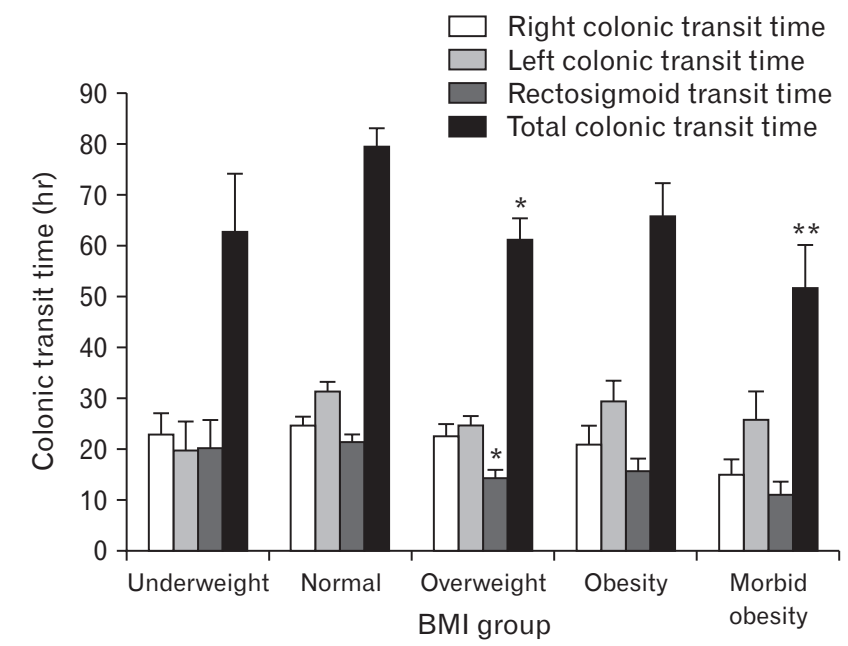

Figure 2. Relationship between body mass index (BMI) and total and segmental colonic transit time in constipated patients. By comparison with patients of $\mathrm{BMI}$ in the normal range, overweight patients have shorter rectosigmoid transit time and shorter total colonic transit time $\left({ }^{\star} P<0.01\right)$. In addition, patients of the morbid obesity group have shorter total colonic transit time than patients of the normal BMI group $\left({ }^{*} P<0.05\right)$. 
Table 2. Characteristics of the Different Groups of Constipated Subjects According to Body Mass Index Group

\begin{tabular}{|c|c|c|c|c|c|c|c|}
\hline \multirow[b]{2}{*}{ Variables } & \multirow[b]{2}{*}{ Total } & \multicolumn{5}{|c|}{ BMI group $\left(\mathrm{kg} / \mathrm{m}^{2}\right)$} & \multirow[b]{2}{*}{$P$-value } \\
\hline & & $\begin{array}{c}\text { Underweight } \\
<18.5\end{array}$ & $\begin{array}{c}\text { Normal } \\
18.5-<25\end{array}$ & $\begin{array}{c}\text { Overweight } \\
25-<30\end{array}$ & $\begin{array}{l}\text { Obesity } \\
30-<35\end{array}$ & $\begin{array}{l}\text { Morbid obesity } \\
\quad \geq 35\end{array}$ & \\
\hline \multicolumn{8}{|l|}{ Demographics } \\
\hline Number & $354(100)$ & $13(4)$ & $171(48)$ & $113(32)$ & $34(10)$ & $23(6)$ & \\
\hline Age (yr) & $46.0 \pm 15.9$ & $38.9 \pm 10.3$ & $43.9 \pm 16.7$ & $48.6 \pm 15.2$ & $51.5 \pm 14.2$ & $44.9 \pm 13.6$ & 0.011 \\
\hline Female gender & $297(84)$ & $12(92)$ & $151(88)$ & $86(76)$ & $27(79)$ & $21(91)$ & 0.047 \\
\hline $\operatorname{BMI}\left(\mathrm{kg} / \mathrm{m}^{2}\right)$ & $25.5 \pm 5.5$ & $17.2 \pm 1.1$ & $22.1 \pm 1.8$ & $26.7 \pm 1.4$ & $31.9 \pm 1.5$ & $40.0 \pm 4.9$ & \\
\hline \multicolumn{8}{|l|}{ Clinical phenotype } \\
\hline Functional constipation & $215(61)$ & $8(4)$ & $93(43)$ & $75(35)$ & $19(9)$ & $20(9)$ & 0.023 \\
\hline IBS-C & $139(39)$ & $5(4)$ & $78(56)$ & $38(27)$ & $15(11)$ & $3(2)$ & \\
\hline Defecation disorders & $243(69)$ & $10(77)$ & $115(67)$ & $77(68)$ & $27(79)$ & $14(61)$ & 0.548 \\
\hline \multicolumn{8}{|l|}{ Scales } \\
\hline LS-constipation & $6.0 \pm 2.5$ & $6.2 \pm 2.4$ & $6.0 \pm 2.6$ & $6.0 \pm 2.6$ & $6.2 \pm 2.4$ & $5.5 \pm 1.8$ & 0.886 \\
\hline LS-bloating & $5.1 \pm 2.9$ & $4.9 \pm 3.4$ & $5.0 \pm 3.0$ & $5.5 \pm 2.7$ & $4.9 \pm 3.0$ & $4.5 \pm 2.2$ & 0.408 \\
\hline LS-abdominal pain & $4.2 \pm 2.9$ & $6.0 \pm 3.1$ & $3.8 \pm 3.0$ & $4.7 \pm 2.8$ & $4.3 \pm 3.1$ & $3.0 \pm 1.8$ & 0.005 \\
\hline Bristol stool form & $2.1 \pm 1.3$ & $2.4 \pm 1.6$ & $2.0 \pm 1.3$ & $2.2 \pm 1.2$ & $2.0 \pm 1.4$ & $2.1 \pm 0.8$ & 0.828 \\
\hline \multicolumn{8}{|l|}{ CTT (hr) } \\
\hline Right CTT & $22.9 \pm 21.5$ & $22.9 \pm 14.3$ & $24.7 \pm 20.7$ & $22.5 \pm 24.5$ & $20.8 \pm 20.9$ & $15.0 \pm 14.2$ & 0.323 \\
\hline Left CTT & $28.2 \pm 22.4$ & $19.7 \pm 19.9$ & $31.3 \pm 23.0$ & $24.6 \pm 19.9$ & $29.3 \pm 23.6$ & $25.7 \pm 26.3$ & 0.078 \\
\hline RSTT & $17.9 \pm 17.2$ & $20.2 \pm 19.2$ & $21.4 \pm 18.6$ & $14.3 \pm 15.4^{\mathrm{a}}$ & $15.7 \pm 13.8$ & $11.0 \pm 12.2$ & 0.002 \\
\hline Total CTT & $69.9 \pm 43.3$ & $62.8 \pm 40.3$ & $79.5 \pm 44.2$ & $61.2 \pm 41.9^{\mathrm{a}}$ & $65.8 \pm 36.8$ & $51.7 \pm 39.5^{\mathrm{b}}$ & 0.001 \\
\hline
\end{tabular}

${ }^{a} P<0.01$ by comparison with patients with body mass index (BMI) in the normal range.

${ }^{\mathrm{b}} \mathrm{P}<0.05$ by comparison with patients with $\mathrm{BMI}$ in the normal range.

$P<0.05$ was considered significant.

IBS-C, irritable bowel syndrome with constipation; LS, Likert scale; CTT, colonic transit time; RSTT, rectosigmoid transit time.

Quantitative parameters are expressed as mean $\pm \mathrm{SD}$ and qualitative parameters are shown as $\mathrm{n}(\%)$.

RSTT ( $P=0.005)$, while the right CTT and total CTT were not significantly correlated with age.

\section{Characteristics of Constipation According to Body Mass Index}

Female gender was more prevalent in underweight and morbid obesity patients, while BMI increased with age. Both FC and IBS$\mathrm{C}$ was more frequent in patients with normal weights. Underweight patients reported the highest abdominal pain severity $(P=0.005)$.

Right and left CTT were not different between the BMI groups. In contrast, total CTT $(P=0.001)$ and $\operatorname{RSTT}(P=0.002)$ decreased as BMI increased (Fig. 2). RSTT was lowest in overweight patients $(P=0.005)$, and total CTT was lowest in the overweight $(P=0.004)$ and in the morbidly obese groups $(P=0.034)$ as compared with constipated patients with normal-range BMI.

CTT in the right part and the left part of the colon were poorly associated with $\mathrm{BMI}(P=0.065$ and $P=0.111$, respectively); in contrast, the RSTT and total CTT were negatively associated with BMI $(P<0.001$ and $P<0.001$, respectively $)$.

\section{Characteristics of Constipation According to the Site of Delay}

The gender ratio, $\mathrm{BMI}$, clinical phenotype of constipation, frequency of DD, stool form, severity of constipation, and bloating were not different among constipated patients classified according to the site of delay (Table 3).

In contrast, right or left colon delay $(P<0.001)$ was found in patients of increased age. More severe abdominal pain $(P=0.022)$ was found in patients with right colon delay.

\section{Predictors for Total and Segmental Colonic Transit Time}

The linear regression model for total and segmental CTT was adjusted for age, BMI, gender, clinical phenotype, DD, symptom severity, and Bristol stool form shows different association with the total and segmental CTT.

(1) Age was associated with left CTT $(P=0.006)$ and RSTT $(P=0.004)$. 
Table 3. Characteristics of the Different Groups of Constipated Subjects According to the Site of Delay

\begin{tabular}{|c|c|c|c|c|c|}
\hline \multirow{2}{*}{ Variables } & \multirow{2}{*}{ Total } & \multicolumn{3}{|c|}{ Site of delay } & \multirow{2}{*}{$P$-value } \\
\hline & & Right colon & Left colon & Rectosigmoid & \\
\hline \multicolumn{6}{|l|}{ Demographics } \\
\hline Number & $354(100)$ & $122(34)$ & $150(42)$ & $82(23)$ & \\
\hline Age (yr) & $46.0 \pm 15.9$ & $46.4 \pm 17.1^{\mathrm{a}}$ & $49.7 \pm 14.2^{\mathrm{b}}$ & $38.8 \pm 14.5$ & $<0.001$ \\
\hline Female gender & $297(84)$ & $98(80)$ & $125(83)$ & $74(90)$ & 0.163 \\
\hline $\operatorname{BMI}\left(\mathrm{kg} / \mathrm{m}^{2}\right)$ & $25.5 \pm 5.5$ & $25.5 \pm 6.0$ & $25.9 \pm 5.0$ & $24.8 \pm 5.7$ & 0.397 \\
\hline \multicolumn{6}{|l|}{ Clinical phenotype } \\
\hline Functional constipation & $215(61)$ & $70(33)$ & $89(41)$ & $56(26)$ & 0.264 \\
\hline IBS-C & $139(39)$ & $52(37)$ & $61(44)$ & $26(19)$ & \\
\hline Defecation disorders & $243(69)$ & $84(69)$ & $102(68)$ & $57(70)$ & 0.970 \\
\hline \multicolumn{6}{|l|}{ Scales } \\
\hline LS-constipation & $6.0 \pm 2.5$ & $6.1 \pm 2.5$ & $6.0 \pm 2.5$ & $5.7 \pm 2.5$ & 0.623 \\
\hline LS-bloating & $5.1 \pm 2.9$ & $5.4 \pm 2.8$ & $5.2 \pm 2.9$ & $4.6 \pm 2.9$ & 0.129 \\
\hline LS-abdominal pain & $4.2 \pm 2.9$ & $4.6 \pm 2.9^{c}$ & $4.2 \pm 2.8$ & $3.5 \pm 3.0$ & 0.022 \\
\hline Bristol stool form & $2.1 \pm 1.3$ & $2.2 \pm 1.2$ & $2.0 \pm 1.3$ & $2.0 \pm 1.3$ & 0.499 \\
\hline \multicolumn{6}{|l|}{ CTT (hr) } \\
\hline Right CTT & $22.9 \pm 21.5$ & $35.9 \pm 27.1$ & $18.4 \pm 14.6$ & $12.0 \pm 11.0$ & $<0.001$ \\
\hline Left CTT & $28.2 \pm 22.4$ & $17.7 \pm 15.9$ & $42.6 \pm 22.4$ & $17.2 \pm 14.5$ & $<0.001$ \\
\hline RSTT & $17.9 \pm 17.2$ & $10.0 \pm 11.2$ & $15.8 \pm 12.7$ & $33.4 \pm 21.4$ & $<0.001$ \\
\hline Total CTT & $69.9 \pm 43.3$ & $63.6 \pm 42.7$ & $79.0 \pm 44.9$ & $62.6 \pm 38.3$ & 0.003 \\
\hline
\end{tabular}

${ }^{\mathrm{a}} P<0.01$ as compared with patients with delayed transit in the rectosigmoid area.

${ }^{\mathrm{b}} P<0.001$ as compared with patients with delayed transit in the rectosigmoid area.

${ }^{\mathrm{c}} P<0.05$ as compared with patients with delayed transit in the rectosigmoid area.

$P<0.05$ was considered significant.

BMI, body mass index; IBS-C, irritable bowel syndrome with constipation; LS, Likert scale; CTT, colonic transit time; RSTT, rectosigmoid transit time.

Quantitative parameters are expressed as mean $\pm \mathrm{SD}$ and qualitative parameters are shown as $\mathrm{n}(\%)$.

(2) BMI was associated with RSTT $(P<0.001)$ and total $\operatorname{CTT}(P=0.001)$.

(3) The severity of constipation was associated with total CTT $(P=0.019)$. The severity of bloating was associated with RSTT $(P$ $=0.007)$, while the severity of abdominal pain was not associated with any segmental CTT or with total CTT.

(4) The stool form was associated with left CTT $(P=0.016)$ and total CTT $(P=0.010)$.

(5) In contrast, gender, clinical phenotype, or the presence of DD were not associated with total or segmental CTT.

\section{Discussion}

This study includes a large group of constipated subjects and shows that some clinical features (gender, severity of abdominal pain, clinical phenotype, and DD) are not associated with total or segmental CTT. In contrast, the association of age, BMI, severity of constipation, severity of bloating, and Bristol stool form differ according to the segment studied. Right CTT is associated with BMI and self-reported severity of constipation; left CTT is associated with age, and the Bristol stool form; RSTT was inversely correlated with age, BMI, and positively with the severity of bloating. Finally, total CTT was associated with BMI, the severity of constipation, and the Bristol stool form.

It was previously shown that age was associated with constipation via the modification of motor and secretory functions of the gastrointestinal tract. ${ }^{26}$ The first result was the importance of age in the left CTT and RSTT in constipated subjects. There were no differences of mean age, and total and segmented CTTs amongst the different clinical groups of constipated patients. A study using radionuclides in healthy subjects showed that older subjects have a slower CTT compared to younger subjects, and BMI does not influence CTT. ${ }^{27}$

We have not found a positive correlation between total CTT and age, however we have identified a positive correlation between the left CTT and age. On the contrary, we found a negative correlation between RSTT and age. This work shows the importance of the RSTT delay in the youngest patients (Table 1), which is in 
agreement with studies showing that children have a stagnation in the rectosigmoid area. ${ }^{4}$ Physiological changes of CTT with age could be related to significant changes of intestinal and colonic neuropeptides with age, ${ }^{28}$ and a decrease of the number and volume of interstitial cells of Cajal. ${ }^{29}$ This finding implies that the type of delay will change with age.

In healthy subjects, no association between BMI, and total and segmental CTT has been found, ${ }^{30}$ whereas this study showed a significant negative relationship between BMI and RSTT in constipated patients. A significant decrease of RSTT and an increase of stool frequency in overweight patients was previously described in IBS patients, ${ }^{15}$ but the authors pooled the different IBS phenotypes (diarrhea, constipation, mixed). Our results suggest for the first time that there is an inverse linear relationship between BMI and RSTT in constipated subjects.

There is a discrepancy in the current literature regarding the characteristics of patients with slow transit constipation. Some studies reported lower BMI associated to lower total caloric intake ${ }^{10,31}$ whereas others did not. ${ }^{32}$ In a large cohort of 35, 000 healthy French subjects, our group did not identify any association between FC and $\mathrm{BMI}{ }^{12} \mathrm{~A}$ recent meta-analysis has found an increased chance of diarrhea in overweight subjects. ${ }^{33}$ In obese patients eligible for bariatric surgery, there is a higher incidence of constipation than diarrhea ${ }^{12}$ regardless of the type of enrollment (patients before bariatric surgery vs patients with functional gastrointestinal disorders). ${ }^{34}$

Finally, FC was associated with low BMI, while IBS-C was associated with normal weight. ${ }^{35}$ This study shows no interaction between RSTT, BMI, and the clinical phenotype (IBS-C or FC). In contrast, we found that overweight, constipated patients have lower RSTT and lower total CTT than patients with BMIs in the normal range. Bile acid metabolism could provide a mechanism that could explain this association. ${ }^{36,37}$ A positive linear relationship between weight, serum bile acid concentration, and an increase of serum bile acid was found in obese patients. ${ }^{38}$ In addition, new drugs that inhibit ileal bile acid transporters, like elobixibat, could be helpful in treating chronic constipation. ${ }^{39}$

The severity of constipation was associated with the right CTT and the total CTT, but not the clinical phenotype. Despite similar CTTs, IBS-C patients reported harder stools, more severe constipation, bloating and abdominal pain compared to the FC patients (Supplementary Table 1). Although they had similar stool consistency, DD patients reported more severe constipation, bloating, and abdominal pain compared to non-DD patients. However, the severity of the symptoms was not associated with the BMI in constipated subjects in the present study. This finding is contrary to a previous study that showed an association between BMI and symptoms in IBS patients, but the authors used all 3 IBS phenotypes (diarrhea, constipation, and mixed). ${ }^{15}$

The present study shows that the severity of the constipation reported by the patient is positively correlated with the right CTT, the left CTT, and the total CTT (Supplementary Table 3). Similarly, as shown in Supplementary Table 3, the Bristol stool form is negatively associated with the right CTT, the left CTT, the RSTT, and the total CTT, showing the importance of the use of this scale in clinical studies. ${ }^{40}$ In contrast, the severity of abdominal pain, and the severity of bloating are only correlated with the right CTT and the RSTT, respectively. In the present study that included only constipated patients; gender was not a factor associated with total and segmental CTT.

We have previously presented the importance of the different embryologic origin of the different parts of the colon associated with different vascularization and innervation. ${ }^{25}$ This study shows that the intensity of constipation evaluated by the patient was associated with a delay of total CTT by delay in the 2 first parts of the colon, while transit in the terminal intestine is associated with demographic parameters (age and BMI).

In this study, constipation was defined clinically according to the Rome III criteria, and in all patients a measurement of total and segmental CTT was performed to characterize the site of delay. ${ }^{25}$ Our results allow us to assess that the measure of the total and segmental CTT is not a useful parameter to separate constipated patients into FC and IBS-C patients. In addition, the presence of DD was not associated with delayed RSTT and defecatory disorders (Supplementary Table 1), which is in agreement with the results of a previous study. ${ }^{41}$ In contrast, it was found that age and BMI are 2 physiological determinants of the RSTT.

One limitation of this study is that the "Single marker-Multiple ingestion-Single film" method was optimized for CTT in the normal range (24 hours to 72 hours), however underestimates delayed $\mathrm{CTT}^{42}$ Nevertheless, a correction factor applied on these values with a compartmental model would increase the significance of the reported relationship. ${ }^{42}$

Another limitation of the present study is that we cannot exclude the well-known switching between clinical phenotypes. In a 12-month period, it was observed that one third of FC changed to IBS-C, and one third of IBS-C changed to $\mathrm{FC}^{43}$ suggesting the existence of "a continuum, rather than as in isolation" ${ }^{44}$ of these phenotypes.

Patients were recruited in a single tertiary center, specialized in the evaluation of constipated subjects, which could explain the high 
rate of patients with DD (75\%), which is in the high range of estimates. ${ }^{2}$ We did not record the patients' dietary patterns; we advised the patients to have a varied diet, in accordance with the recommendations of the French Nutrition and Health Program (Programme National Nutrition Santé), ${ }^{45}$ and have sufficient water intake.

A strong point of our study is the fact that patients were recruited in a single tertiary center in which most patients complained of resistant symptoms (constipation, bloating, or abdominal pain), and were already evaluated by a general practitioner or gastroenterologist for a long period, decreased the switching between clinical phenotypes. Patients had chronic constipation and the results found were independent of the clinical phenotype. Another advantage was that the CTT measurements were obtained using the state-of-theart technique of CTT measurement.

In summary, the present study has shown that in constipated patients, their age and their BMI had a negative linear relationship with RSTT. In addition, both factors presented different correlations with CTT: BMI negatively correlated with total CTT, while age positively correlated with the transit time of the left part of the colon. The relationship between BMI and age with CTT was similar in the 2 groups of constipated patients. Patients with FC presented higher BMI and were in the same age group as the IBS$\mathrm{C}$ patients. Transit times were similar between the 2 groups of patients, while the severity of abdominal pain was higher in the IBS-C group. These results confirm that there is no difference in patients with constipation; the only difference is in the severity of abdominal pain. ${ }^{19}$ Further studies are needed to evaluate the influence of age, $\mathrm{BMI}$, and gender in healthy subjects in order to define normal or delayed CTT values.

\section{Supplementary Materials}

Note: To access the supplementary tables mentioned in this article, visit the online version of Journal of Neurogastroenterology and Motility at http://www.jnmjournal.org/, and at https://doi. org/10.5056/jnm18167.

\section{Financial support: None.}

\section{Conflicts of interest: None.}

Author contributions: Michel Bouchoucha performed the research, contributed to the design of the study, performed data analysis, participated in the interpretation of data, wrote the article, revised the article for its content, and approved its final version;
Marinos Fysekidis performed data analysis, participated in the interpretation of data, wrote the article, revised the article for its content, and approved its final version; Pierre Rompteaux, Gheorge Airinei, and Jean-Marc Sabate participated in the selection of the patients and revised the article for its content; and Robert Benamouzig participated in the selection of the patients, contributed in the design of the study, revised the article's content and gave final approval for the version to be published.

\section{References}

1. Longstreth GF, Thompson WG, Chey WD, Houghton LA, Mearin F, Spiller RC. Functional bowel disorders. Gastroenterology 2006;130:1480-1491.

2. Bharucha AE, Wald A, Enck P, Rao S. Functional anorectal disorders. Gastroenterology 2006;130:1510-1518.

3. Lanfranchi GA, Bazzocchi G, Brignola C, Campieri M, Labò G. Different patterns of intestinal transit time and anorectal motility in painful and painless chronic constipation. Gut 1984;25:1352-1357.

4. Arhan P, Devroede G, Jehannin B, et al. Segmental colonic transit time. Dis Colon Rectum 1981;24:625-629.

5. Orr WC, Chen CL. Aging and neural control of the GI tract: IV. Clinical and physiological aspects of gastrointestinal motility and aging. Am J Physiol Gastrointest Liver Physiol 2002;283:G1226-G1231.

6. Lock G. Physiology and pathology of the oesophagus in the elderly patient. Best Pract Res Clin Gastroenterol 2001;15:919-941.

7. Andy UU, Vaughan CP, Burgio KL, Alli FM, Goode PS, Markland AD. Shared risk factors for constipation, fecal incontinence, and combined symptoms in older U.S. adults. J Am Geriatr Soc 2016;64:e183e188.

8. Misra S, Lee A, Gensel K. Chronic constipation in overweight children. JPEN J Parenter Enteral Nutr 2006;30:81-84.

9. Pourhoseingholi MA, Kaboli SA, Pourhoseingholi A, et al. Obesity and functional constipation; a community-based study in Iran. J Gastrointestin Liver Dis 2009;18:151-155.

10. Chen HB, Huang Y, Song HW, et al. Clinical research on the relation between body mass index, motilin and slow transit constipation. Gastroenterology Res 2010;3:19-24.

11. Le Pluart D, Sabaté JM, Bouchoucha M, Hercberg S, Benamouzig R, Julia C. Functional gastrointestinal disorders in 35,447 adults and their association with body mass index. Aliment Pharmacol Ther 2015;41:758767.

12. Fysekidis M, Bouchoucha M, Bihan H, Reach G, Benamouzig R, Catheline JM. Prevalence and co-occurrence of upper and lower functional gastrointestinal symptoms in patients eligible for bariatric surgery. Obes Surg 2012;22:403-410.

13. Delgado-Aros S, Locke GR 3rd, Camilleri M, et al. Obesity is associated with increased risk of gastrointestinal symptoms: a population-based study. Am J Gastroenterol 2004;99:1801-1806.

14. Talley NJ, Howell S, Poulton R. Obesity and chronic gastrointestinal 
tract symptoms in young adults: a birth cohort study. Am J Gastroenterol 2004;99:1807-1814.

15. Sadik R, Björnsson E, Simrén M. The relationship between symptoms, body mass index, gastrointestinal transit and stool frequency in patients with irritable bowel syndrome. Eur J Gastroenterol Hepatol 2009;22:102-108.

16. De Schryver AM, Keulemans YC, Peters HP, et al. Effects of regular physical activity on defecation pattern in middle-aged patients complaining of chronic constipation. Scand J Gastroenterol 2005;40:422-429.

17. Sturtzel B, Elmadfa I. Intervention with dietary fiber to treat constipation and reduce laxative use in residents of nursing homes. Ann Nutr Metab 2008;52(suppl 1):54-56.

18. Yang J, Wang HP, Zhou L, Xu CF. Effect of dietary fiber on constipation: a meta analysis. World J Gastroenterol 2012;18:7378-7383.

19. Bouchoucha M, Devroede G, Mary F, Bon C, Bejou B, Benamouzig R. Painful or mild-pain constipation? a clinically useful alternative to classification as irritable bowel syndrome with constipation versus functional constipation. Dig Dis Sci 2018;63:1763-1773.

20. Bouchoucha M, Devroede G, Bon C, Bejou B, Mary F, Benamouzig R. Is-it possible to distinguish irritable bowel syndrome with constipation from functional constipation? Tech Coloproctol 2017;21:125-132.

21. Bouchoucha M, Devroede G, Arhan P, et al. What is the meaning of colorectal transit time measurement? Dis Colon Rectum 1992;35:773782.

22. Bharucha AE. Update of tests of colon and rectal structure and function. J Clin Gastroenterol 2006;40:96-103.

23. Lee BE, Kim GH. How to perform and interpret balloon expulsion test. J Neurogastroenterology Motil 2014;20:407-409.

24. Rao SS, Patcharatrakul T. Diagnosis and treatment of dyssynergic defecation. J Neurogastroenterol Motil 2016;22:423-435.

25. Bouchoucha M, Devroede G, Bon C, Raynaud JJ, Bejou B, Benamouzig R. How many segments are necessary to characterize delayed colonic transit time? Int J Colorectal Dis 2015;30:1381-1389.

26. Yamamoto K, Kitano Y, Shuang E, et al. Decreased lipid absorption due to reduced pancreatic lipase activity in aging male mice. Biogerontology 2014;15:463-473.

27. Madsen JL. Effects of gender, age, and body mass index on gastrointestinal transit times. Dig Dis Sci 1992;37:1548-1553.

28. El-Salhy M, Sandström O. How age changes the content of neuroendocrine peptides in the murine gastrointestinal tract. Gerontology 1999;45:17-22.

29. Gomez-Pinilla PJ, Gibbons SJ, Sarr MG, et al. Changes in interstitial cells of Cajal with age in the human stomach and colon. Neurogastroenterol Motil 2011;23:36-44.

30. Jung HK, Kim DY, Moon IH. Effects of gender and menstrual cycle on colonic transit time in healthy subjects. Korean J Intern Med 2003;18:181-186.
31. Preston DM, Lennard-Jones JE. Severe chronic constipation of young women: 'idiopathic slow transit constipation'. Gut 1986;27:41-48.

32. Nullens $S$, Nelsen T, Camilleri M, et al. Regional colon transit in patients with dys-synergic defaecation or slow transit in patients with constipation. Gut 2012;61:1132-1139.

33. Eslick GD. Gastrointestinal symptoms and obesity: a meta-analysis. Obes Rev 2012;13:469-479.

34. Bouchoucha M, Fysekidis M, Julia C, et al. Functional gastrointestinal disorders in obese patients. The importance of the enrollment source. Obes Surg 2015;25:2143-2152.

35. Bouchoucha M, Fysekidis M, Julia C, et al. Body mass index association with functional gastrointestinal disorders: differences between genders. Results from a study in a tertiary center. J Gastroenterol 2016;51:337345.

36. Peters SA, Edogawa S, Sundt WJ, et al. Constipation-predominant irritable bowel syndrome females have normal colonic barrier and secretory function. Am J Gastroenterol 2017;112:913-923.

37. Vijayvargiya P, Busciglio I, Burton D, Donato L, Lueke A, Camilleri M. Bile acid deficiency in a subgroup of patients with irritable bowel syndrome with constipation based on biomarkers in serum and fecal samples. Clin Gastroenterol Hepatol 2018;16:522-527.

38. Prinz P, Hofmann T, Ahnis A, et al. Plasma bile acids show a positive correlation with body mass index and are negatively associated with cognitive restraint of eating in obese patients. Front Neurosci 2015;9:199.

39. Nakajima A, Seki M, Taniguchi S. Determining an optimal clinical dose of elobixibat, a novel inhibitor of the ileal bile acid transporter, in Japanese patients with chronic constipation: a phase II, multicenter, double-blind, placebo-controlled randomized clinical trial. J Gastroenterol 2018;53:525534.

40. Saad RJ, Rao SS, Koch KL, et al. Do stool form and frequency correlate with whole-gut and colonic transit? Results from a multicenter study in constipated individuals and healthy controls. Am J Gastroenterol 2010;105:403-411.

41. Cowlam S, Khan U, Mackie A, Varma JS, Yiannankou Y. Validity of segmental transit studies used in routine clinical practice, to characterize defaecatory disorder in patients with functional constipation. Colorectal Dis 2008; 10:818-822.

42. Bouchoucha M, Thomas SR. Error analysis of classic colonic transit time estimates. Am J Physiol Gastrointest Liver Physiol 2000;279:G520G527.

43. Wong RK, Palsson OS, Turner MJ, et al. Inability of the Rome III criteria to distinguish functional constipation from constipation-subtype irritable bowel syndrome. Am J Gastroenterol 2010;105:2228-2234.

44. Mearin F, Lacy BE, Chang L, et al. Bowel disorders. Gastroenterology Online First: 18 Feb 2016. dio: 10.1053/j.gastro.2016.02.031.

45. Hercberg S, Chat-Yung S, Chaulia M. The french national nutrition and health program: 2001-2006-2010. Int J Public Health 2008;53:68-77. 